\title{
Through the Patients' Eyes: The Experience of End-Stage Renal Disease Patients Concerning the Provided Nursing Care
}

\author{
Areti Stavropoulou ${ }^{1}$, Maria G. Grammatikopoulou ${ }^{2}$, Michail Rovithis ${ }^{1}$, \\ Konstantina Kyriakidi ${ }^{3}$, Andriani Pylarinou ${ }^{3}$ and Anastasia G. Markaki ${ }^{3, *}$ \\ 1 Department of Nursing, Technological Educational Institute of Crete, Estavromenos, Irakleio 71004, Greece; \\ aretistavropoulou@gmail.com (A.S.); rovithismihail@gmail.com (M.R.) \\ 2 Department of Nutrition \& Dietetics, Alexander Technological Educational Institute, Sindos 57400, Greece; \\ maria@nutr.teithe.gr \\ 3 Department of Nutrition \& Dietetics, Technological Educational Institute of Crete, Estavromenos, \\ Irakleio 71004, Greece; kwnstantinakyr@hotmail.gr (K.K.); andrianapilarinou@hotmail.gr (A.P.) \\ * Correspondence: anmarkaki@staff.teicrete.gr; Tel.: +30-28430-29491; Fax: +30-28430-26683
}

Academic Editors: Joanne Reid and Helen Noble

Received: 17 May 2017; Accepted: 19 July 2017; Published: 21 July 2017

\begin{abstract}
Chronic kidney disease is a condition that affects both the physical and mental abilities of patients. Nursing care is of pivotal importance, in particular when end-stage renal disease (ESRD) patients are concerned, since the quality of the provided care may severely influence the patient's quality of life. This is why it is important to explore patient experiences concerning the rendered care. However, limited up-to-date studies have addressed this issue. The aim of the present study was to stress the experiences of ESRD patients concerning the provided nursing care in the hemodialysis unit at the University Hospital in Heraklion, Crete. A qualitative methodological approach was used, based on the principles of phenomenological epistemology. Semi-structured interviews were conducted, and open-ended questions were applied to record how patients experienced the rendered care during dialysis. The recorded data were analyzed via qualitative content analysis, which revealed three main themes: 'Physical Care', 'Psychological Support' and 'Education'. Patients' views were conceptualized into sub-themes within each main theme. The interviews revealed the varied and distinct views of ESRD patients, indicating that the rendered care should be individualized.
\end{abstract}

Keywords: chronic kidney disease; hemodialysis patients; nursing care; qualitative study; patient experience; ESRD; renal disease; nephrology nurse; nephrology care

\section{Introduction}

Chronic kidney disease (CKD) is currently affecting $18.4 \%$ of the European population [1], with end-stage renal disease (ESRD) patients in particular receiving a disproportionate share of health care resources and spending a great amount of time using treatment facilities. Since the performance of the first hemodialysis in a human by Hass in 1924, it still remains the most preferred treatment for ESRD today [2,3]. According to the latest European Renal Association - European Dialysis and Transplantation Association registry data [3], in Greece, there have been an estimated 1.1 million CKD patients (10\% of the total population), with 13,359 of them being ESRD patients. Among ESRD Greek patients, approximately $75 \%(10,029)$ are on hemodialysis [4], indicating that this specific renal replacement therapy (RRT) is the therapeutic option for the majority of the Greek ESRD patients. Consequently, the financial burden on the Greek health care system, along with ESRD patients' burden, is extremely high. 
The objectives of care for patients on hemodialysis include providing sufficient dialysis, maintaining vascular access, ensuring adequate nutrition, minimizing hospitalization, and prolonging life and its quality [5]. Nursing care, on the other hand, involves interactive actions built on the ethical dimension between the caregiver and the client [6]. Hemodialysis in particular requires specialized nursing care that extends beyond technical knowledge and the suggested Nursing Care Plans (NCP). It includes therapeutic and interpersonal relationships, as well as prompt responses to physical symptoms, functional limitations, psychosocial disruptions, and knowledge needs [6,7].

According to Kimmel [8], hemodialysis is a lifelong treatment that significantly and sometimes adversely affects patients' physical and mental abilities, with depression, anxiety and fatigue being common issues $[9,10]$. There are also a plethora of additional stressors, including biochemical imbalance, physiological changes, neurological disturbances, cognitive impairment, and sexual dysfunction, all associated with ESRD [11]. For hemodialysis patients who spend a considerable portion of their life receiving treatment, nursing care is of pivotal importance, and the identification of the bottlenecks hampering nursing care would contribute to an ameliorated relationship between nephrology nurses and patients and inevitably, to a better quality of life for the latter. However, literature is scarce on the experience and beliefs of ESRD patients receiving care.

The nursing care offered on hemodialysis patients entails unique characteristics in relation to other nursing plans. Frequent patient visits (usually three times a week) lead to an increased proximity to the nursing staff [12]. Moreover, the clinical environment where hemodialysis nurses are called to serve is demanding and stressful, leading many nurses to develop burnout syndrome [13-15]. In particular, one of the main obstacles to the provision of nursing care among ESRD patients concerns the increased workload, augmented by various factors such as the need for different care services, the limited number of employed nurses and other health professionals, and the lack of a strategy for systematic education and guidance of patients [16]. However, according to a cohort study performed among 320 hemodialysis patients from 14 general hospitals situated in Athens and the peninsula of Peloponnese, the majority of patients reported satisfaction with regards to the availability of information prior to the initiation of hemodialysis and the provision of nursing care. Moreover, patients were very/extremely satisfied with the provided care in terms of the duration of the changing sera/intravenous solutions, the kindness and empathy expressed by nurses, as well as from their professionalism and applied techniques, throughout the provided care [17]. However, some international studies have reported a lack of information concerning the available treatments [18], and low satisfaction from the provided nursing care [19].

In Greece, the nursing care provided to ESRD patients is of particular importance due to the large proportion of patients suffering from chronic renal failure and the great number of those on hemodialysis. Additionally, the quality of the rendered care is associated with the role of nephrology nurses, with specialized expertise and patient-nurse interaction being important predictors affecting the quality of the provided care. This is why patients' experiences could provide valuable feedback for the nurses in order to reassess, set goals and improve the quality and safety of the provided care. In this context, the present study aimed to explore the experiences of hemodialysis patients concerning the provided nursing care, using a qualitative methodological approach, based on phenomenological epistemology.

\section{Materials and Methods}

A qualitative methodological approach based on phenomenological epistemology was used, as this allows researchers to explore patients' lived experiences in detail.

\subsection{Sample and Recruitment}

The study was conducted at the University Hospital of Heraklion, in Crete, Greece, during the year 2016. Participants were recruited from the hemodialysis unit via a non-random purposeful sampling strategy, as the aim was to identify and involve patients whose experience of care during hemodialysis 
might produce valuable information on the topic. Inclusion criteria were (1) being an adult, (2) being on hemodialysis for more than a year, and (3) being able to understand and articulate effortlessly in the Greek language. All nurse managers and doctors at the hemodialysis unit were informed of the study's purpose and were asked to identify potential participants matching the inclusion criteria. Each potential participant was addressed individually and informed of the study's nature prior to participation. In total, 10 patients aged between 34-68 years old agreed to participate and provided informed consent. Patient characteristics are presented in Table 1.

Table 1. Participants' demographic data ( $n$ or mean \pm SD).

\begin{tabular}{cc}
\hline Men/Women $(n)$ & $7 / 3$ \\
Age (years) & $56 \pm 4$ \\
Marital status (married/single) $(n)$ & $6 / 4$ \\
Education (primary/secondary/tertiary) $(n)$ & $4 / 3 / 3$ \\
Employment (retired/self-employed/employee/unemployed) & $5 / 2 / 2 / 1$ \\
Duration of hemodialysis (years) & $5 \pm 4$ \\
\hline
\end{tabular}

\subsection{Data Collection}

All interviews were conducted by an experienced researcher in a quiet area chosen by the participant, either within the hospital or in the patients' residence. Each participant provided oral permission prior to the interviews' digital recording. Semi-structured, face-to-face interviews were conducted, facilitated by open-ended guide questions, in order to encourage patients to share their views and gain an in-depth understanding of their experience concerning nursing care during hemodialysis. The interviews lasted approximately 15-25 min for each participant, and the recorded interviews were then transcribed verbatim.

\subsection{Data Analysis}

A qualitative content analysis was used to analyze the data. Words or phrases of the participants' statements consisted the units of analysis. Common concepts and themes that reflected the experiences of patients were identified from analyzing the participants' reports. Common concepts were grouped into categories. Comparing and contrasting the emerged categories led to the development of three main themes. Emerging sub-themes within each main theme reflected patients' experience of the provided nursing care.

\subsection{Ethical Considerations}

Prior to the commencement of the study, the research proposal, a consent form, a participant information sheet and risk assessment form were submitted to the Research Ethics Committee of the University General Hospital, situated in Heraklion, Crete. Ethical approvals were granted by the Scientific Committee, as well as the nurse managers and the medical directors of the hemodialysis unit before the recruitment and data collection. All data were handled according to the Helsinki Declaration and its latter amendments. Voluntary participation and anonymity were emphasized, and participants were assured of confidentiality concerning their responses. Confirmation was provided that all information collected through the interviews would be used solely for the stated research purposes. Participants were also informed of their right to withdraw from the study at any stage without facing consequences affecting the routine care they received. Informed consent was provided prior to the interviews and all recordings and written information remained anonymous. Code names were given to all participants for better presentation of the results.

\section{Results}

Analysis of the interviews capturing patients' experience of the care rendered in the hemodialysis unit revealed three main themes: (1) 'Physical Care', (2) 'Psychological Support' and (3) 'Education' 
(Table 2). Patients' views and perceptions were conceptualized into sub-themes within each main theme. Table 3 stresses verbatim quotes defining the patients' views on nursing and ambulatory care during hemodialysis, with the use of pseudonyms throughout.

Table 2. Interviews' main themes and sub-themes.

\begin{tabular}{ccc}
\hline Physical Care & Psychological Support & Education \\
\hline Preserving dignity & Showing empathy and acceptance & Personal effort \\
Demonstrating technical skills & Developing interpersonal relationships & Professional skill \\
Reassuring safe practices & Communicating effectively & \\
Maintaining a responsive environment & & \\
\hline
\end{tabular}

Table 3. Verbatim quotes defining the patients' views on nursing care during hemodialysis.

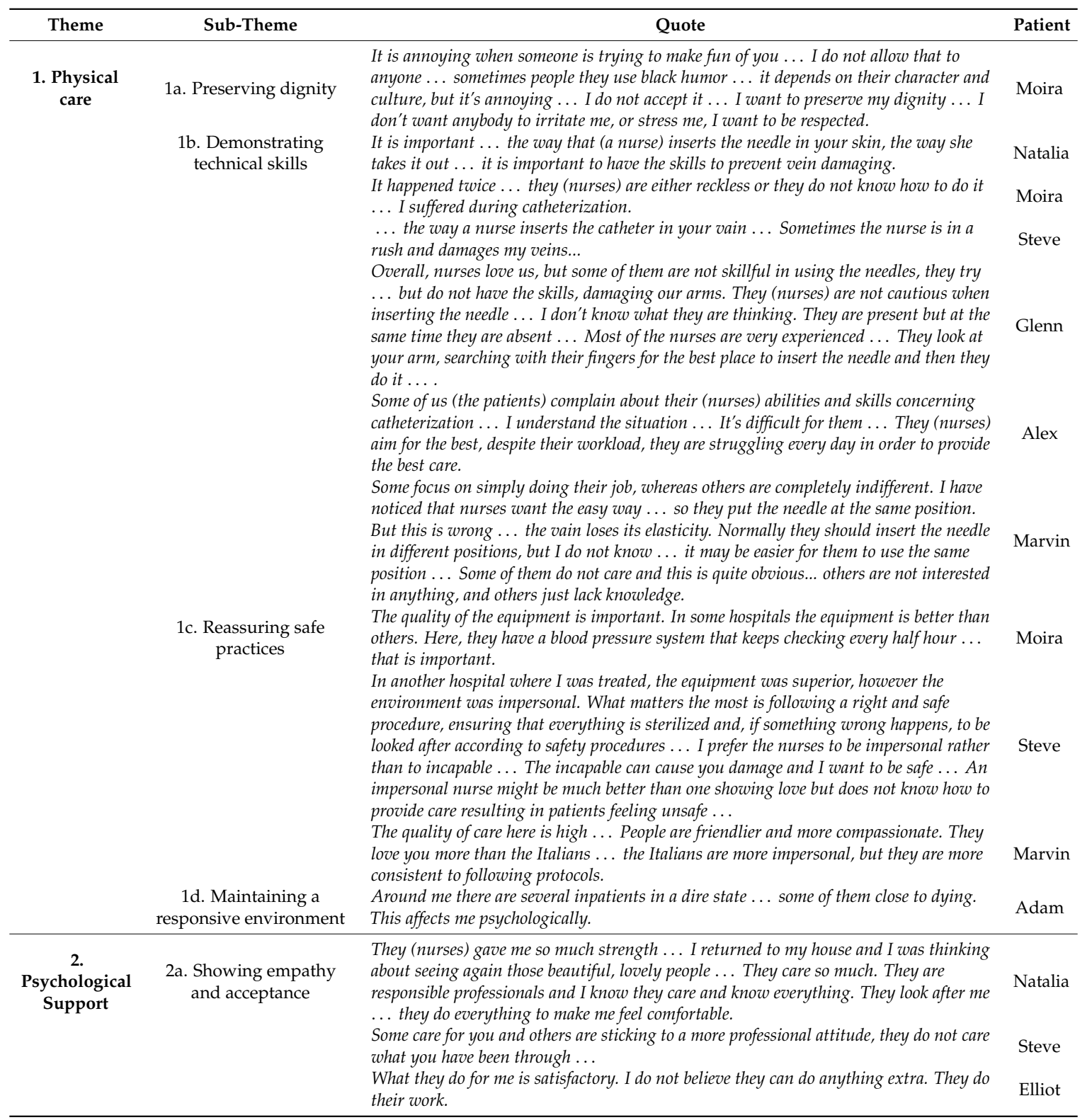


Table 3. Cont.

\begin{tabular}{|c|c|c|c|}
\hline Theme & Sub-Theme & Quote & Patient \\
\hline & $\begin{array}{l}\text { 2b. Developing } \\
\text { interpersonal } \\
\text { relationships }\end{array}$ & $\begin{array}{l}\text { I have no complaints ... nurses and doctors, they love me and I love them back... } \\
\text { They accept me with so much love ... people (nurses and doctors) that I have not met } \\
\text { before. I did not want to start hemodialysis, instead, I wanted to die. But when they } \\
\text { embraced me with such love, all these people... I will not forget their faces, their } \\
\text { kindness. Awesome experience! They supported me psychologically. I see their faces and } \\
\text { I think... they are all my children. Through all these I loved everyone in the unit, the } \\
\text { patients too ... I looked at them with so much empathy ... } \\
\text { They are all very good to me and I admire their courage to struggle with so } \\
\text { difficult situations } \\
\text { Good communication ... it is not perfect, but also not that bad. Everything is OK, when } \\
\text { I need something, I have it. In general, it is not like being next to you all the time. I have } \\
\text { lived this experience too, not here though ... Some people are more emotional, they stand } \\
\text { by you, helping a lot by discussing things ... this helped me a lot psychologically when I } \\
\text { was in a terrible state. } \\
\text { It is their duty to communicate with the patients ... we understand however the } \\
\text { burdens. This is the reality... } \\
\text { The heavy workload impedes communication ... doctors cannot be with you every single } \\
\text { day. Sometimes you can realize the lack of communication ... they (doctors) cannot stay } \\
\text { next to you to ask how you are doing ... They have a heavy workload, some are tired, } \\
\text { others are very interested in you, others are a bit indifferent. }\end{array}$ & Daniel \\
\hline 3. Education & 3b. Professional skills & 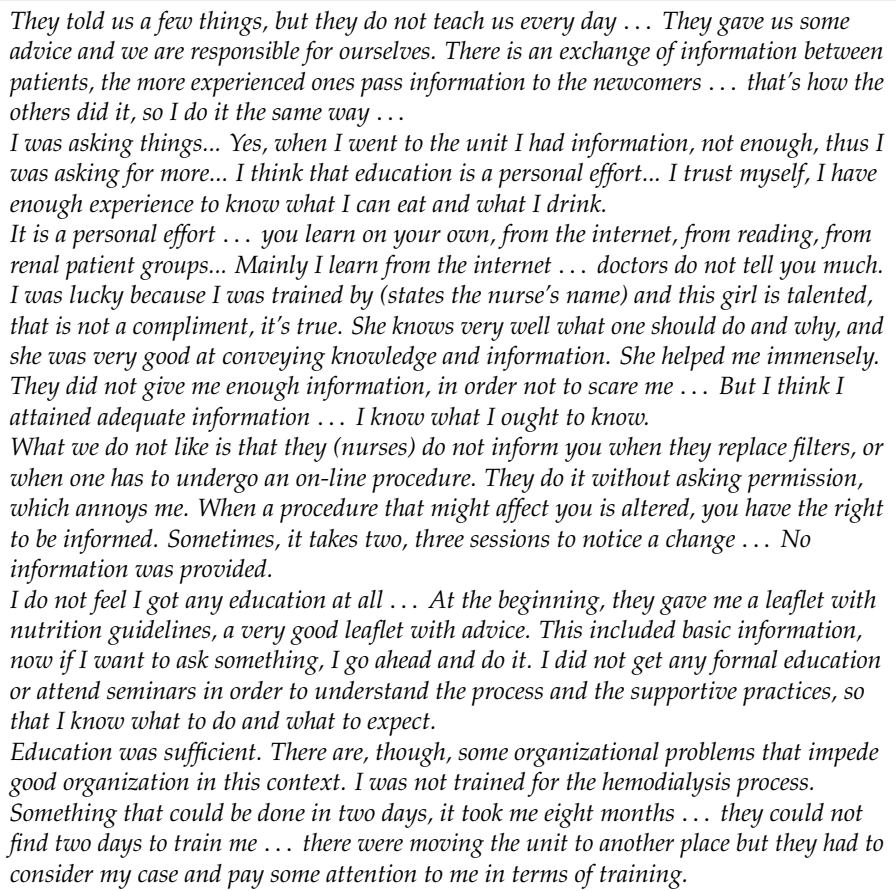 & Adam \\
\hline
\end{tabular}

\subsection{Physical Care}

Issues related to the physical care seemed to be of paramount importance for ESRD patients. Preservation of decency, nurses' cautiousness and skillfulness and adherence to safe practices were indicated by the participants as important factors. Additionally, the importance of preserving dignity and empathy throughout the nursing process was stressed, as indicated by Moira's statement (Table 3).

Additionally, the majority of participants focused the abilities and technical skills demonstrated by the nurses during the provision of care. Natalia stressed the importance of demonstrating and applying excellent practice during catheterization, whereas cautiousness and skillfulness appeared to be equally important in ensuring patients' comfort. It also seemed that the responders viewed nurses' cautiousness and skillfulness as distinct issues from affectionate care, as indicated by Glenn's statement. The participants also referred to the factors that might impede nurses from applying the best practice such as the heavy workload (Alex), whereas Marvin argued that cautiousness was actually a matter of professional attitude and knowledge. 
Concerning the third sub-theme, "Reassuring safe practices", the safety and quality of equipment were identified as key issues in providing safe and quality care. Another interesting finding was that cautiousness, capacity, safety procedures and the quality of the equipment used were considered more important according to Steve than having an empathic and effective relationship with the staff. On the other hand, Marvin compared his experience on care in two different units, hinting at the equally important issue of being compassionate.

Participants additionally referred to environmental issues as part of the adequate quality of the physical care and reassuring therapeutic process. Adam, for instance, highlighted the importance of a responsive and reassuring environment.

\subsection{Psychological Support}

Patients' experiences also focused on issues of psychological support in terms of provision of empathic care, the development of effective relationships with the staff, and good communication patterns. The first sub-theme concerned "Showing empathy and acceptance", which produced either evolving feelings, as seen in Natalia's statement, or more moderate experiences, as stressed by Steve and Elliot.

Concerning the interpersonal relationships with the nursing staff, participants associated the issue with concepts of acceptance, strength, support and mutual affection, as indicated by Natalia's and Daniel's statements. According to the first, the building of empathic relationships with other hemodialysis patients was additionally important, whereas Belinda pointed out several obstacles impeding the development of good relationships, such as the demanding hospital environment.

Issues regarding communication patterns seemed to be of major concern for the responders. Mostly, they expressed skepticism about communication practices, and some of them referred to issues that hindered effective communication between staff and patients. While Moira stressed the value of good communication, other responders focused mainly on the obstacles impeding effective communication from the staff. Although Alex believed that good communication consisted of a nursing duty, he experienced a different reality.

\subsection{Education}

Patients' education appeared to be another issue of discussion and skepticism. Overall, responders felt that although education consisted of an important part of care, it was neglected and left upon each patient's personal effort, as pointed out by Adam, Steve and Marvin.

Additionally, participants stressed the value of training provided by the staff. Adam and Belinda reflected the importance of receiving accurate and timely information by skilled and experienced nurses. Marvin, on the other hand, revealed the need to receive information on time. Moira's experience focused on the absence of formal educational activities, and the effect this might have on patient anxiety and uncertainty for the future. Adam delineated the factors impeding the provision of formal patient education.

\section{Discussion}

The research herein identified three main themes of concern regarding nursing care among hemodialysis patients: physical care, psychological support and patient education. Multiple factors were associated with each domain, which contributed to understanding the provided nursing care from the patient's point of view.

The rendered care involved personal dignity, nurses' technical skills and safe practices, and the maintenance of a responsive environment. Hemodialysis patients in particular require constant physical and emotional support. Nurses, on the other hand, ought to understand patients, build trust and respond to their needs through encouragement $[20,21]$. To date, a number of studies have examined the experiences of CKD patients regarding the nursing care provided to them. In Kenya, ESRD patients reported neutral satisfaction with the provided care, mainly due to the way nurses 
attended to patients [22]. According to Chochinov and associates [23], ESRD patients face unique challenges as they move towards the end of life; simultaneously, the prevalence of depression is also high in patients with CKD [24]. Additionally, patients are unwilling to become a burden or liability, and question their identity, pride, and self-image [25]. Thus, nurses should adopt an individualized approach to supporting psychological well-being and helping patients adapt to a changing lifestyle [21].

Nursing competencies and the assurance of safe practices were other important issues highlighted by the participants. A recent study in Iran revealed that ESRD patients expected nurses to attain the knowledge and skills to perform all care-related activities at ease [26]. Before meeting the patients' needs, nurses require a certain understanding of technology, technical skills, knowledge, and experience [27]. The participants herein compared competencies, care protocols and skills between hospitals and nurses. In Kenya, ESRD patients noted the importance of equipment and the nurse-patient ratio as important factors affecting patient satisfaction [22]. Janssen and associates [28] explored the preferences of 4,518 patients undergoing hemodialysis. The findings showed that patients considered safety and safe practices as a more important element of their treatment than life expectancy [28]. According to a recent study on Greek ESRD patients, nurses' technical and communication skills, competencies, timely intervention, and attitudes such as kindness, empathy, and respect for patients' needs, diversities and professionalism, were essential features of the provided care [15]. However, it should be noted that the lack of human resources, guidelines, and regulations in certain hospitals often confuse nurses working in hemodialysis [27]. According to Garbin and Chmielewski [29], in order to provide safe and quality of care, nephrology nurses should fully understand the role of the health care team members and be able to allow other people to take care of their patients.

Research has showed that CKD patients experience emotional distress even in the earlier stages of disease progression [30] and in the majority, experience low feelings of personal control and low levels of illness coherence [31]. Patients have described the experience of hemodialysis as a daily struggle to accept illness and adjust to the treatment [32]. As Jonasson and Gustafsson [33] have noted, the challenge for nurses is to be able to support patients who are in a transitional phase of their life and be able to help patients regain lost stability and well-being.

The need to support patients psychologically has been highlighted in recent publications. Both the National Service Framework (NSF) for renal services [34] and the NSF for long-term conditions [35] indicate that care planning must recognize patients' psychological needs in order to minimize mental health deterioration. According to Sedgewick [36], as well as Wright and Weinman [37], clinical psychologists can be a great asset in a multidisciplinary renal unit. However, it is important for nurses, who interact with patients more frequently, to obtain patients' views on whether and when psychological support would be beneficial, as well as who they feel ought to provide it [38].

Leatherland [38] argued that an important action that all nurses should perform in order to ameliorate patient psychological health is to be available for patients to talk to. According to Swanson's theory of caring [39], being with patients involves being emotionally present and facilitating their passage through life transformation by providing information, explanations, support, acceptance, emotion, alternatives, and feedback [39]. According to a qualitative descriptive phenomenological study conducted among 14 nurses at two distinct hemodialysis centers in Korea, nurses are not psychologically and emotionally inactive while providing care. On the contrary, they experienced sadness regarding patients' lives, which involved enduring hemodialysis treatment, and they endeavored to establish good relationships and become comfortable with clients, their family and friends [40]. In the study herein, the participants greatly valued the supportive mechanism formed by the nursing staff and the other patients. As Auer [25] noted, for some patients, the regular trips to the hospital for treatment can be a welcome social activity.

Clinical practice guidelines for the treatment of kidney disease advocate the provision of education to patients [41,42]. Research has showed that timely and adequate patient education can balance modality selection $[43,44]$, prepare for a better initiation of dialysis [45], and promote independence, 
while also encouraging self-management [46,47]. Recent advances in CKD patient education recommend the development of training programs based on the principles of the adult learning theory, which initially assesses individuals' ability and willingness to learn [48,49]. Demonstration and instruction are the most widely used teaching activities. However, if different trainers are involved in the training process and each of them demonstrates things differently, this results in the patients becoming confused. In addition, instructions and demonstrations should be simple and concise [49].

According to a multinational study conducted by the European Kidney Patients' Federation (CEAPIR) [37], CKD patients reported to be overall satisfied with the education received on their disease and treatment, although information seemed mostly to have been focused on one modality, with patients involved in modality selection being more satisfied with their treatment. However, studies on the USA using ESRD patients only have showed different results. According to Fadem et al. [16], ESRD patients are not uniformly advised about all possible treatment methods, which results in a fairly moderate satisfaction with their pre-treatment education. In the present study, patients identified the importance of personal effort on attaining adequate education and disease knowledge, exchanging information between more experienced patients and less experienced ones, and the nursing staff attaining disease-specific education. Harrison [50] argued that as far as patient education is concerned, many nurses lack the required skills, knowledge, and self-esteem; this is why tutoring nurses is essential in order to develop their ability and confidence [38]. In Kenya, ESRD patients valued greatly the post-dialyses guidelines received by nurses, as well as the assignment of a renal counselor to each patient and the availability of a nutritionist in the renal unit [22].

According to Kazley and associates [51], the majority of clinicians agree that there is typically a wide range of reactions among CKD patients. Additionally, because of various complications, as well as physical and psychological problems, ESRD patients are in need of continuous and comprehensive patient care to ensure adherence to therapy [26]. Our study presented the varied and distinct views of ESRD patients concerning nursing care during hemodialysis, and indicated that each patient should be treated accordingly and individually.

Qualitative research would provide valuable insight into the effectiveness of CKD patients' views and perceptions from the provided nursing care. The cultural characteristics of the patients who participated in the study, as well as their strong dependence on the medical and nursing staff, which is common in the Greek health system, may have affected the variety of data, as well as prevented the participants from expressing themselves freely and sharing their concerns about the delivery and quality of the nursing care. Future studies could investigate whether specific components of the nursing care could be improved through targeted educational interventions in order to ameliorate nursing care quality.

\section{Conclusions and Implications of Nursing Practice}

The current qualitative analysis of the experiences of CKD patients could potentially facilitate our understanding of how specific characteristics and competences of nephrology nurses have a direct impact on the quality of the provided health care. This is imperative, as the common concepts and themes that reflected the experiences of patients revealed from this study, are often related directly to the performance and quality of the nursing care. This highlights the importance of patients' views and perceptions as key performance determinants of healthcare delivery. The findings could help nursing students and nurses who lack experience of CKD care to understand patient needs and deliver care of better quality.

Acknowledgments: The authors wish to acknowledge the help of all participants. This research was funded by the Research Committee of the Technological Educational Institute of Crete, under the 1st Internal Research Support Program, within the frame of the project titled: Prevalence of Protein-Energy Wasting in End-Stage Renal Disease (ESRD) patients and detection of determinant factors. 
Author Contributions: Areti Stavropoulou and Anastasia G. Markaki conceived and designed the study. Areti Stavropoulou, Konstantina Kyriakidi and Andriani Pylarinou collected the data. Areti Stavropoulou additionally analyzed and interpreted the data. Maria G. Grammatikopoulou wrote the majority of the manuscript, Areti Stavropoulou and Michail Rovithis participated in manuscript drafting and Anastasia G. Markaki supervised all procedures and corrected the manuscript.

Conflicts of Interest: The authors declare no conflict of interest. The founding sponsors had no role in the design of the study; in the collection, analyses, or interpretation of data; in the writing of the manuscript, and in the decision to publish the results.

\section{References}

1. Hill, N.R.; Fatoba, S.T.; Oke, J.L.; Hirst, J.A.; O'Callaghan, C.A.; Lasserson, D.S.; Hobbs, F.D.R. Global Prevalence of Chronic Kidney Disease-A Systematic Review and Meta-Analysis. PLoS ONE 2016, 11, e0158765. [CrossRef] [PubMed]

2. Kolff, W.J.; Berk, H.T.J. The Artificial kidney: A dialyzer with a great area. Acta Med. Scand. 1944, CXVII, 121-134.

3. Pippias, M.; Kramer, A.; Noordzij, M.; Afentakis, N.; de la Torre, F.A.; Ambuhl, P.M.; Madre, M.I.A.; Monzón, F.A.; Åsberg, A.; Bonthuis, M.; et al. The European Renal Association-European Dialysis and Transplant Association Registry Annual Report 2014: A summary. Clin. Kidney J. 2017, 10, 1-6. [CrossRef] [PubMed]

4. ERA-EDTA Registry. ERA-EDTA Registry Annual Report 2015; Academic Medical Center, Department of Medical Informatics: Amsterdam, The Netherlands, 2017.

5. Ifudu, O. Care of Patients Undergoing Hemodialysis. N. Engl. J. Med. 1998, 339, 1054-1062. [CrossRef] [PubMed]

6. Rodrigues, T.A.; Lappann Botti, N.C. Providing and receiving nursing care during hemodialysis. Acta Paul. Enferm. 2009, 22, 528-530. [CrossRef]

7. Gomez, N. Nephrology nursing scope and standards from practice. American Nephrology Nurses Association: Pitman, NJ. Available online: https://www.annanurse.org/professional-development/ practice/scope-of-practice/nephrology-nursing (accessed on 5 May 2017).

8. Kimmel, P.L. Psychosocial factors in dialysis patients. Kidney Int. 2001, 59, 1599-1613. [CrossRef] [PubMed]

9. Chen, C.K.; Tsai, Y.C.; Hsu, H.J.; Wu, I.W.; Sun, C.Y.; Chou, C.C.; Lee, C.C.; Tsai, C.R.; Wu, M.S.; Wang, L.J. Depression and suicide risk in hemodialysis patients with chronic renal failure. Psychosomatics 2010, 51, 528-528.e6. [CrossRef]

10. Frazão, C.M.; Araújo, A.D.; Lira, A.L. Implementation of nursing process to the patient submitted to hemodialysis. Rev. Enferm. UFPE 2013, 7, 824-830.

11. Kavurmac1, M.; Cantekin, I.; Tan, M. Burnout levels of hemodialysis nurses. Ren. Fail. 2014, 36, $1038-1042$. [CrossRef] [PubMed]

12. Hayes, B.; Douglas, C.; Bonner, A. Work environment, job satisfaction, stress and burnout among haemodialysis nurses. J. Nurs. Manag. 2015, 23, 588-598. [CrossRef] [PubMed]

13. Karakoc, A.; Yilmaz, M.; Alcalar, N.; Esen, B.; Kayabasi, H.; Sit, D. Burnout Syndrome Among Hemodialysis and Peritoneal Dialysis Nurses. Iran. J. Kidney Dis. 2016, 10, 395-404. [PubMed]

14. Tejada-Tayabas, L.M.; Partida-Ponce, K.L.; Hernández-Ibarra, L.E. Coordinated hospital-home care for kidney patients on hemodialysis from the perspective of nursing personnel. Rev. Lat. Am. Enfermagem 2015, 23, 225-233. [CrossRef] [PubMed]

15. Ferentinou, E.; Giannakopoulou, M.; Prezerakos, P.; Sachlas, A.; Theofilou, P.; Zyga, S. Measuring beliefs and satisfaction regarding nursing care among Greek patients on hemodialysis. J. Behav. Health 2016, 5, 117-122. [CrossRef]

16. Fadem, S.Z.; Walker, D.R.; Abbott, G.; Friedman, A.L.; Goldman, R.; Sexton, S.; Buettner, K.; Robinson, K.; Peters, T.G. Satisfaction with renal replacement therapy and education: The American Association of Kidney Patients survey. Clin. J. Am. Soc. Nephrol. 2011, 6, 605-612. [CrossRef] [PubMed]

17. Palmer, S.C.; de Berardis, G.; Craig, J.C.; Tong, A.; Tonelli, M.; Pellegrini, F.; Ruospo, M.; Hegbrant, J.; Wollheim, C.; Celia, E. Patient satisfaction with in-centre haemodialysis care: An international survey. BMJ Open 2014, 4, e005020. [CrossRef] [PubMed] 
18. Wang, L.J.; Chen, C.K. The Psychological Impact of Hemodialysis on Patients with Chronic Renal Failure, Renal Failure-The Facts; Polenakovic, M., Ed.; InTech: Rijeka, Croatia, 2012.

19. Finnegan-John, J.; Thomas, V.J. The Psychosocial Experience of Patients with End-Stage Renal Disease and Its Impact on Quality of Life: Findings from a Needs Assessment to Shape a Service. ISRN Nephrol. 2013, 2013, 8. [CrossRef] [PubMed]

20. Deal, B.; Grassley, J.S. The lived experience of giving spiritual care: A phenomenological study of nephrology nurses working in acute and chronic hemodialysis settings. Nephrol. Nurs. J. 2012, 39, 471-481, 496, quiz 482. [PubMed]

21. Sturesson, A.; Ziegert, K. Prepare the patient for future challenges when facing hemodialysis: Nurses' experiences. Int. J. Qual. Stud. Health Wellbeing. 2014, 9, 22952. [CrossRef] [PubMed]

22. Ndambuki, J. The level of patients' satisfaction and perception on quality of nursing services in the Renal unit, Kenyatta National Hospital Nairobi, Kenya. Open J. Nurs. 2013, 3, 186-194. [CrossRef]

23. Chochinov, H.M.; Johnston, W.; McClement, S.E.; Hack, T.F.; Dufault, B.; Enns, M.; Thompson, G.; Harlos, M.; Damant, R.W.; Ramsey, C.D.; et al. Dignity and Distress towards the End of Life across Four Non-Cancer Populations. PLoS ONE 2016, 11, e0147607. [CrossRef] [PubMed]

24. Horsburgh, M. Self-care of well adult Canadians and adult Canadians with end stage renal disease. Int. J. Nurs. Stud. 1999, 36, 443-453. [CrossRef]

25. Auer, J. Psychological perspectives. In Renal Nursing, 2nd ed.; Thomas, N., Ed.; Baillière Tindall: Edinburgh, UK, 2002.

26. Nobahar, M.; Tamadon, M.R. Barriers to and facilitators of care for hemodialysis patients; A qualitative study. J. Renal. Inj. Prev. 2016, 5, 39-44. [CrossRef] [PubMed]

27. Bennett, P.N. Technological intimacy in haemodialysis nursing. Nurs. Inq. 2011, 18, 247-252. [CrossRef] [PubMed]

28. Janssen, I.M.; Gerhardus, A.; von Gersdorff, G.D.; Baldamus, C.A.; Schaller, M.; Barth, C.; Scheibler, F. Preferences of patients undergoing hemodialysis-Results from a questionnaire-based study with 4,518 patients. Patient Preference Adherence. 2015, 9, 847-855. [CrossRef] [PubMed]

29. Garbin, M.G.; Chmielewski, C.M. Job analysis and role delineation: LPN/LVNs and hemodialysis technicians. Nephrol. Nurs. J. 2013, 40, 225-240. [PubMed]

30. Clarke, A.L.; Yates, T.; Smith, A.C.; Chilcot, J. Patient's perceptions of chronic kidney disease and their association with psychosocial and clinical outcomes: A narrative review. Clin. Kidney J. 2016, 9, 494-502. [CrossRef] [PubMed]

31. Wu, C.C.; Lin, C.C.; Hsieh, H.F.; Chang, S.C. Lived experiences and illness representation of Taiwanese patients with late-stage chronic kidney disease. J. Health Psychol. 2016, 21, 2788-2798. [CrossRef] [PubMed]

32. Guerra-Guerrerro, V.; Plazas, M.D.; Cameron, B.L.; Salas, A.V.; Gonzalez, C.G. Understanding the life experience of people on hemodialysis: Adherence to treatment and quality of life. Nephrol. Nurs. J. 2014, 41, 289-297, 316, quiz 298. [PubMed]

33. Jonasson, K.; Gustafsson, L.K. You Live as Much as You Have Time To: The Experience of Patients Living with Hemodialysis. Nephrol. Nurs. J. 2017, 44, 35-42.

34. Department of Health. The National Service Framework for Renal Services Part One: Dialysis and Transplantation. Stationery Office: London, 2004. Available online: http:/ /www.dh.gov.uk/asset-Root/04/ 07/05/25/04070525.pdf (accessed on 3 March 2017).

35. Department of Health. The National Service Framework for Long-term Conditions. 2005. Available online: http:/ / www.dh.gov.uk/assetRoot/04/10/53/69/04105369.pdf (accessed on 10 February 2017).

36. Sedgewick, J. Psychological issues in renal failure. In Principles and Practice of Renal Nursing; Challinor, P., Sedgewick, J., Eds.; Stanley Thornes: Cheltenham, UK, 1998; pp. 36-55.

37. Wright, S.; Weinman, J. Health psychologists make an important contribution to care. Br. Med. J. 1995, 311, 948. [CrossRef]

38. Leatherland, S. Continuing Care of the Renal Patient: A Guide for Nurses. Dial. Transplant. 2007, 1-6. [CrossRef]

39. Swanson, K.M. Empirical development of a middle range theory of caring. Nurs. Res. 1991, 40, 161-166. [CrossRef] [PubMed]

40. Kim, S.; Lee, H.Z.; Hwang, E.; Song, J.; Kwon, H.J.; Choe, K. Lived experience of Korean nurses caring for patients on maintenance haemodialysis. J. Clin. Nurs. 2016, 25, 1455-1463. [CrossRef] [PubMed] 
41. Kelly, J.; Stanley, M.; Harris, D. Caring for Australians with Renal Impairment (CARI). Acceptance onto dialysis guidelines. The CARI Guidelines-Caring for Australians with Renal Impairment. 2005. Available online: http://www.cari.org.au/Dialysis/dialysis\%20acceptance/Predialysis_education_aug-2005.pdf (accessed on 20 July 2017).

42. Department of Health. The Expert Patient: A New Approach to Chronic Disease Management for the 21st Century. Stationery Office: London, 2001. Available online: http://www.dh.gov.uk/assetRoot/04/01/85/ 78/04018578.pdf (accessed on 5 January 2017).

43. Van Biesen, W.; De Vecchi, A.; Dombros, N.; Dratwa, M.; Gokal, R.; LaGreca, G.; Van Olden, W.; Walls, J.; Wauters, J.P.; Lameire, N. The referral pattern of end-stage renal disease patients and the initiation of dialysis: A European perspective. Perit. Dial. Int. 1999, 19, S273-S275. [PubMed]

44. Mehrotra, R.; Marsh, D.; Vonesh, E.; Peters, V.; Nissenson, A. Patient education and access of ESRD patients to renal replacement therapies beyond in-center hemodialysis. Kidney Int. 2005, 68, 378-390. [CrossRef] [PubMed]

45. Stehman-Breen, C.O.; Sherrard, D.J.; Gillen, D.; Caps, M. Determinants of type and timing of initial permanent hemodialysis vascular access. Kidney Int. 2000, 57, 639-645. [CrossRef] [PubMed]

46. Curtin, R.B.; Mapes, D.L. Health care management strategies of long-term dialysis survivors. Nephrol. Nurs. J. 2001, 28, 385-392. [PubMed]

47. Van Biesen, W.; van der Veer, S.N.; Murphey, M.; Loblova, O.; Davies, S. Patients' Perceptions of Information and Education for Renal Replacement Therapy: An Independent Survey by the European Kidney Patients' Federation on Information and Support on Renal Replacement Therapy. PLoS ONE 2014, 9, e103914. [CrossRef] [PubMed]

48. Finkelstein, F.O.; Ezekiel, O.O.; Raducu, R. Development of a peritoneal dialysis program. Blood Purif. 2011, 31, 121-124. [CrossRef] [PubMed]

49. Bergjan, M.; Schaepe, C. Educational strategies and challenges in peritoneal dialysis: A qualitative study of renal nurses' experiences. J. Clin. Nurs. 2016, 25, 1729-1739. [CrossRef] [PubMed]

50. Harrison, A. The mental health needs of patients in physical care settings. Nurs. Stand. 2001, 15, 47-56. [CrossRef] [PubMed]

51. Kazley, A.S.; Johnson, E.E.; Simpson, K.N.; Chavin, K.D.; Baliga, P. Health care provider perception of chronic kidney disease: knowledge and behavior among African American patients. BMC Nephrol. 2014, 15, 112. [CrossRef] [PubMed] 